\title{
Da Antropologia aos Fundamentos Antropológicos da Educação Considerações Iniciais
}

\author{
Iael de Souza ${ }^{1}$
}

\begin{abstract}
Resumo
0 homem como problema, em si e para si, sua humanização, formação e autoconstrução; as possibilidades da realização humana ao colocar o homem como problema de si mesmo; a natureza essencial da educação, o seu sentido amplo e seu fundamento antropológico; a humanização desumanizadora e a formação deformadora no contexto do modo de produção e vida capitalista; as contradições da sociabilidade do capital e a repercussão no processo de fazer-se homem dos homens. Estas são algumas das questões inicialmente refletidas neste artigo, a partir do materialismo histórico-dialético.
\end{abstract}

Palavras-chave: Antropologia. Educação informal. Formação humana.

\section{FROM ANTHROPOLOGY TO ANTHROPOLOGICAL EDUCATION FUNDAMENTALS - INICIAL CONSIDERATIONS}

\begin{abstract}
Man as a problem in itself and for itself, his humanization, training and self-help housing construction. The possibilities of human achievement by placing the human being as the problem itself. The essential nature of education, its broad sense and its anthropological basis. The humanization and dehumanizing deformadora formation in the context of the capitalist mode of production and life. The contradictions of sociality of capital and the repercussions on the process of making a man of men. These are some of the issues initially reflected in this article, from the historical materialism dialectic.
\end{abstract}

Keywords: Anthropology. Informal education. Human formation.

1 Doutoranda da Faculdade de Educação da Unicamp. Integrante do grupo de pesquisa do Lapplane, da Unicamp. Professora da Universidade Federal do Piauí. Mestre em Ciências Sociais pela Unesp - Marília. iaeldeo@gmail.com. 
Procura-se abordar as relações entre a antropologia e a educação não de uma perspectiva culturalista, a mais comum e propagada, mas, sim, de uma perspectiva histórico-materialista-dialética, tendo como cerne de constituição do homem o trabalho, complexo dos complexos, que funda mas não esgota o ser social, que, ao criar novas necessidades a partir da satisfação daquelas ligadas diretamente à produção e reprodução de suas condições materiais de existência, cria outras e, portanto, outros complexos sociais, como a cultura, que adquire uma certa autonomia relativa em relação ao momento predominante e fundante, que é o trabalho.

No esteio dessa contextualização, as relações entre antropologia e educação são pensadas enquanto processo de tornar-se homem dos homens, de sua autoconstrução, formação e processo educativo, quando o centro nevrálgico problematizador/problema é o próprio ser social que se faz a si mesmo processualmente, ao longo do seu desenvolvimento histórico-social, ou seja, de acordo com o grau de complexidade alcançado pela organização das relações sociais e de produção organizadas pelos homens, correspondendo a determinadas sociedades, condicionadas pelo nível do desenvolvimento das forças produtivas no tempo e espaço, produzindo-se como gênero humano.

Trata-se de considerações iniciais para auxiliar na construção das mediações entre antropologia e educação, mesmo porque as obras científicas que abordam essas dimensões da vida social, em sua grande maioria, partem de outra perspectiva, como dito anteriormente, que estamos convictos de não ser a mais adequada e apropriada à aproximação mais fidedigna da realidade, pois os fatos, que são atos teleológicos concretizados pelo ser social, ao se objetivarem no mundo entram em relação com os demais objetos e somente são passíveis de serem compreendidos se reconstruirmos as mediações entre todas as objetividades postas, que se intermedeiam e interligam, produzindo a síntese das múltiplas determinações desse real, que, para ser compreendida, necessita que refaçamos a totalidade social.

Espera-se poder auxiliar, principalmente, aqueles que se debruçam na busca por compreender as relações entre a antropologia e educação de modo a tornar sua práxis social mais lúcida, orientando-a a fim de que seus frutos possam 
reorientar sua elaboração e sistematização teórica, criando ações educativas de caráter transformador que articulem seus esforços para gestar novas relações sociais, pautadas em novos valores, capacitadas de produzir um novo homem.

\section{A Dimensão Antropológica do Ser Social na Perspectiva Histórico-Dialética}

O homem não nasce homem, ele se faz homem. Como demonstram Engels (1979), Fischer (1973) e Lukács (Lessa, 1996²), a história humana é a história do fazer-se homem dos homens, do ser natural (biofísico) que se faz e desenvolve como ser social (ontologia histórico-social), da sua construção enquanto gênero humano, estabelecendo os laços de interdependência que universalizam e, ao mesmo tempo, diferenciam os homens, pois a generalização das forças produtivas que produzem as condições materiais para a produção e reprodução da vida, da existência, permitem a diminuição do tempo de trabalho socialmente necessário para satisfazê-la, liberta os homens do trabalho ligado diretamente à subsistência e possibilita a realização do significado realizador do trabalho como ato de vontade e de liberdade do ser humano, individualizando-o, colocando a possibilidade de diversificação da riqueza social pela possibilidade social, universal de realização individual.

Ainda que essas potencialidades estejam impedidas de se realizarem na plenitude das condições histórico-sociais postas em virtude da sociabilidade do capital e seu sistema metabólico, alicerçado na propriedade privada dos meios de produção e das próprias forças produtivas em geral, não acessíveis a toda a humanidade mas apenas a uma ínfima parcela dela - os proprietários privados

\footnotetext{
2 A leitura dos clássicos é essencial. Pela densidade e complexidade da elaboração teórica desses autores/pensadores, porém, muitos acabam sendo vencidos pela falta de persistência. A fim de preparar os espíritos para a empreitada, indicamos a obra de Lessa (1996), que tem o intuito de "facilitar o acesso do leitor não especializado" a um texto "decisivo da filosofia contemporânea" (Lessa, 1996, p. 10).
} 
desses meios e dessas forças de produção: os capitalistas -, elas existem como virtualidades reais, dadas, e evidenciam as contradições presentes nas relações sociais e de produção capitalistas.

Todas as produções humanas, materiais e imateriais, são apropriadas pelo capital e seu sistema societal, servindo aos seus interesses e necessidades, ainda que aparente estar a serviço das necessidades e interesses de toda a humanidade, de modo que não existe neutralidade axiológica nem mesmo na produção científica no contexto do mundo moderno, e isso fica demonstrado pelo fato de que "o estrato científico ligado ao bem-estar de uma classe minoritária ou a ciência bélica se desenvolve com maior eficiência do que as ciências humanas" (Martins, 2013, p. 22). A própria antropologia é oficialmente reconhecida como ciência e ganha legitimidade em pleno século 19, atendendo às necessidades impostas pelo desenvolvimento industrial e pela vida urbana e seu dinamismo nos países centrais, que disputam e concorrem por novos mercados consumidores, por recursos naturais e por força de trabalho abundante e barata para explorar pela colonização e conquista de territórios e de pessoas.

Ao invés de gastos dispendiosos com as prováveis guerras contra os povos nativos - uma das formas de resistência à exploração, subordinação e violência ao seu modo de vida socioeconômico-cultural -, tornou-se muito mais eficaz estudar esses povos, seus costumes, comportamentos e tradições, por intermédio de pesquisas de campo, de observação participante, desenvolvendo o trabalho etnográfico e etnológico, por impregnação lenta e gradual, compreendendo sua organização e funcionamento, em que estão suas forças e fraquezas, para, assim, obter o êxito em "civilizá-los", tornando o diferente inferior em comparação com os ditos povos civilizados, desenvolvidos política, econômica e culturalmente. A riqueza da produção humana, da unidade na diversidade, é reduzida e empobrecida pela padronização sociocultural, que abarca o modo de ser, pensar, fazer, viver, interagir e valorar dos indivíduos sociais.

As ciências, em geral, e a antropologia, em particular, servem aos interesses do capital e seu processo de acumulação exponencial, e não aos verdadeiros interesses e necessidades humanos. Os próprios homens, a partir do momento que tornam a propriedade privada, a divisão técnica-social do trabalho, o trabalho 
assalariado, o Estado e a sociedade de classes, a base da organização de suas relações de trabalho, de propriedade e de produção, constroem um desenvolvimento humano desumanizador, porque o sujeito nesse e desse processo não são os homens, mas o capital, que transforma aqueles pela relação de exploração e propriedade, em coisas, cujo valor básico é medido pelo tempo de trabalho necessário para produzir os meios de existência mínimos e indispensáveis à reprodução de sua própria força de trabalho a fim de que continue vendendo-a até que pereça.

A mudança dessa situação somente será possível com o resgate e a retomada da centralidade do trabalho (enquanto ato de vontade e liberdade humana, indo além do fim em si mesmo, que é a produção das condições materiais de existência) e do ser social, a partir do momento em que a classe explorada, oprimida e coisificada tome consciência de sua condição de classe, reconhecendo-se e identificando-se enquanto classe trabalhadora, construindo sua identidade de classe "em si" para lutar pelas condições que lhe possibilite tornar-se classe "para si" e construir sua hegemonia na luta contra-hegemônica em oposição ao capital. É assim que a antropologia poderá ser ressignificada e redimensionalizada mediante sua apropriação pela classe trabalhadora quando, então, poderá se colocar para além dos interesses de classe, em prol dos interesses de toda a humanidade, uma vez que o critério parametrador das ações humanas será o questionamento sobre o que favorece, ou não, o desenvolvimento das capacidades e potencialidades de todos os seres humanos para além das necessidades de classe, sendo comum a criação das condições sociais que permitam a cada um individualmente realizar-se na plenitude possível posta pelo desenvolvimento das forças produtivas no patamar histórico-social alcançado pela humanidade.

Enquanto continuamos vivendo em uma sociedade de classes, a educação também permanece sendo uma educação de classes e atenderá aos interesses e necessidades da classe dominante, que detêm a hegemonia sob o aparelho de Estado e suas instituições, dentre elas a instituição escolar, sistematizando o processo de ensino-aprendizagem de acordo com as exigências postas pelo mundo do trabalho assalariado capitalista e pela produção direcionada a 
atender os interesses e necessidades do capital, que se utiliza das necessidades humanas (valor de uso) para criar as mercadorias (valor de troca), subsumindo o valor de uso ao valor de troca. Assim, os trabalhadores da educação que se reconhecem enquanto parte da classe trabalhadora em geral e estão cientes das contradições que perpassam as relações e ações educativas na sociedade de classes e da luta de classes, deverão trabalhar as ciências humanas no limite da possibilidade colocada pelo trabalho escolar dentro da organização escolar burocrática-capitalista, de modo a evidenciar as contradições das relações sociais e de produção, reelaborando o conhecimento sobre a práxis humana na sociabilidade do capital, permitindo à classe trabalhadora e aos seus filhos a apropriação, compreensão e sistematização do significado político, econômico e cultural de suas condições (ou da falta delas) de vida e trabalho.

Neste contexto, o ensino institucionalizado, apesar dos seus limites, pode possibilitar a descoberta das condições para a construção de um outro mundo e modo de vida, criando as condições para a construção de um novo homem a partir do momento que vá construindo e contraponto aos valores e ethos capitalista os valores e ethos desse outro mundo e modo de vida que se sonha edificar; sonho que tem sua motivação nas potencialidades reais postas na e pela realidade, embora somente como tendência a fato, ao menos por enquanto, como foi explicado. Mesmo assim, porém, permite-nos sonhar a fim de que, alimentados por esse sonho, possamos, coletivamente, ir construindo as condições e forçando a realização das outras impedidas de se concretizarem para superar e transcender o modo de vida capitalista.

A ciência antropológica pode vir a contribuir com e na criação dessas condições caso parta das, e faça, problematizações ontológicas constituintes, lançando-se do pressuposto ontológico do homem, que é seu fundamento, ou seja, recolocando o ser humano e suas necessidades como fundante e fundamento da organização do modo de vida social, questionando sobre o que é essencial para uma vida boa e para o bem comum, sobre quais valores devem orientar e guiar as ações e relações sociais e de produção, refletindo para além do capital e do ethos capitalista, de modo que possamos, verdadeiramente, ser, reconhecer e nos sentir humanidade, racional e emocionalmente pertencentes ao gênero humano, 
colocando as forças produtivas a favor e em benefício de todos os homens, a fim de que se realize e se possa desfrutar, efetivamente, da riqueza social, uma vez que as condições para o livre-desenvolvimento de todos e cada um estarão dadas e, desta forma, poderemos, de fato, viver e compreender o significado da unidade na diversidade da qual cada um de nós é feito e ajudamos a produzir, pois a diversidade apenas é possível garantindo a todos os indivíduos a possibilidade de realização por meio do trabalho enquanto ato de vontade e liberdade, para além do fim em si mesmo, assegurando, a todos, as condições essenciais e necessárias para produzir e reproduzir a vida e vivê-la. Somente assim é possível falar em "respeito" à diversidade, tendo ciência de que as condições para realizá-la devem ser públicas, ou seja, dadas, pressupostas a todos.

A antropologia deve, portanto, nos auxiliar a refletir e descobrir os alicerces sobre os quais o ser humano deve construir e estruturar o modo de organização das relações sociais e de produção, alicerces estruturais, fundantes e fundamentais ao seu processo de hominização, ou seja, da produção historicizada e consciente de si mesmo e seu mundo, fruto da transformação do mundo natural que, pelo ato humano do trabalho, ganha nova forma, função e significado, portanto, se humaniza e se faz história. A nova e renovada forma dada ao mundo natural, reflexiva e dialeticamente vai produzindo e desenvolvendo a formação humana, seu processo educativo e de aprendizagem. "A educação reproduz, assim, em seu plano próprio, a estrutura dinâmica e o movimento dialético do processo histórico de produção do homem. Para o homem, produzir-se é conquistar-se, conquistar sua forma humana. A pedagogia é antropologia" (Freire, 2005, p. 13).

A busca pelos fundamentos antropológicos da educação, portanto, pode redirecionar e redimensionalizar nossa preocupação com o que real e verdadeiramente importa: "a preocupação em torno do homem e dos homens, como seres no mundo e com o mundo. Em torno do que e de como estão sendo (...), buscando a afirmação dos homens como sujeitos de decisão", refletindo "o sentido mais antropológico do que antropocêntrico de nossa época" (Freire, 2005, p. 31). Como assevera Freire (2005, p. 32), 
Constatar essa preocupação implica, indiscutivelmente, reconhecer a desumanização, não apenas como viabilidade ontológica, mas como realidade histórica. É também, e talvez sobretudo, a partir desta dolorosa constatação que os homens se perguntam sobre a outra viabilidade - a de sua humanização. Ambas, na raiz de sua inconclusão, os inscrevem num permanente movimento de busca. Humanização e desumanização, dentro da história, num contexto real, concreto, objetivo, são possibilidades dos homens como seres inconclusos e conscientes de sua inconclusão.

Mas, se ambas são possibilidades, só a primeira nos parece ser o que chamamos de vocação dos homens. Vocação negada, mas também afirmada na própria negação. Vocação negada na injustiça, na exploração, na opressão, na violência dos opressores. Mas afirmada no anseio de liberdade, de justiça, de luta dos oprimidos pela recuperação de sua humanidade roubada.

Como "ser mais", como superar a desumanização produzida por uma determinada forma de organizar as relações de produção, de trabalho, de propriedade, portanto, por uma determinada maneira de humanização desumanizadora, que forma deformando, que gera riqueza mas a nega para a maioria, eis as questões que a antropologia pode nos ajudar a colocar e descobrir. Novamente se empresta as palavras de Freire, que utilizou as palavras de uma mulher simples do povo para sintetizar o poder do conhecimento, da reflexão, da apropriação dos determinantes históricos, políticos, econômicos e como eles potencializam e possibilitam a tomada de consciência dos indivíduos enquanto sujeitos de sua própria história e as razões e por quês estavam à margem dela. "Gosto de discutir sobre isto porque vivo assim. Enquanto vivo, porém, não vejo. Agora sim, observo como vivo" (Freire, 2005, p. 13).

Recolocar a humanidade e humanização do homem no centro não tem nada de antropocêntrico, mas é a reposição do antropológico, de suas necessidades, das condições essenciais do seu desenvolvimento. É, de fato, compreender o como vivemos, por que vivemos dessa maneira e não de outra, para quem interessa vivermos assim, a quais necessidades atendemos, quais 
valores $^{3}$ valorizamos. É superar o prático-utilitário, as amarras das ilusões apegadas às aparências que procuram justificar e naturalizar o modo como vivemos a vida e como ela é (ou melhor, está sendo), produzindo o senso comum no qual mergulhamos e estamos imersos, vivendo e não vendo, como foi perspicazmente constatado por aquela mulher simples do povo citada por Freire. Afinal, como lembra Freire (2005, p. 13, 14. O itálico é nosso.),

a consciência é essa misteriosa e contraditória capacidade que tem o homem de distanciar-se das coisas para fazê-las presentes, imediatamente presentes. É a presença que tem o poder de presentificar: não é representação, mas condição e apresentação. (...) no processo de totalização da consciência é sempre provocação que a incita a totalizar-se. O mundo é espetáculo, mas sobretudo convocação. E, como a consciência se constitui necessariamente como consciência do mundo, ela é, pois, simultânea e implicadamente, apresentação e elaboração do mundo.

Vejamos, pois, como a antropologia se relaciona com a educação, ou melhor, com a educação em um sentido amplo, não formal, e com a pedagogia, para que possamos compreender melhor o que foi dito a respeito dos seus fundamentos antropológicos.

\footnotetext{
3 A palavra homem significa exatamente aquele que avalia (que valora, atribui valor e significado, justificando a razão de ser das coisas). (...) Valorizar é não ser indiferente. (...) Isto nos permite entender o valor como uma relação de não indiferença entre o homem e os elementos com que se defronta. (...) O homem tem necessidades que precisam ser satisfeitas e este fato leva à valorização e aos valores. (...) Ele reage perante a situação, intervém pessoalmente para aceitar, rejeitar ou transformar. (...) Os valores indicam as expectativas, as aspirações que caracterizam o homem em seu esforço de transcender-se a si mesmo e a sua situação histórica; como tal, marcam aquilo que deve ser em contraposição aquilo que é. A valoração é o próprio esforço do homem em transformar o que é naquilo que deve ser. (...) A partir da valoração é possível definir objetivos para a educação. Considerando que a educação visa a promoção do homem, são as necessidades humanas que irão determinar os objetivos educacionais. E essas necessidades devem ser consideradas em concreto, pois a ação educativa será sempre desenvolvida num contexto existencial concreto (Saviani, 2004, p. 35, 36, 37, 38, 39. O parênteses é nosso.)
} 


\section{A Educação em um Samplo e os Fundamentos Antropológicos da Educação Embasados na Importância Dessa Compreensão}

Primeiramente, precisa-se justificar porque não se tratará, nessa discussão e na perspectiva em que ela está situada, da educação em um sentido restrito, ou seja, da educação formal, escolar, institucional. ${ }^{4}$

A educação escolar, formal, institucionalizada é a apropriação, formatação, organização do patrimônio histórico-cultural acumulado pela humanidade de uma determinada forma, respondendo e servindo às necessidades e interesses de um certo tipo de sociedade historicamente determinada. No caso, a sociedade capitalista, que é uma sociedade de classes e, neste sentido, a educação passa a ser controlada e conduzida hegemonicamente pela classe que domina por meio do aparelho ideológico que é, no modo de produção capitalista, aquele que tem posição dominante por excelência: o escolar. É assim que o sistema de ensino institucionalizado, controlado pelo Estado capitalista, "constitui o instrumento mais acabado de reprodução das relações de produção de tipo capitalista" (Saviani, 2007, p. 23), garantindo a reprodução da divisão técnica-social-hierárquica do trabalho e das desigualdades sociais.

É por isso que essa reflexão não se apoiará na educação formal, mas, sim, na não formal, ou seja, aquela que se constrói desde as relações sociais e de produção, a partir da sociedade, que é a verdadeira educadora, tanto que estrutura e organiza o trabalho escolar, o processo ensino-aprendizagem e a própria estrutura organizacional da escola e demais instituições de ensino conforme suas necessidades. Assim, uma outra escola, uma outra educação, um outro processo de ensino-aprendizagem, com outros métodos de trabalho e avaliação, serão plenamente possíveis quando for superada e positivamente transcendida a sociedade do capital, a sociedade de classes.

${ }^{4}$ Não iremos nos estender para não desviar do foco de reflexão e análise propostas, de modo que procuraremos ser sintéticos, até porque fizemos isso em outros dois artigos. 
$\mathrm{O}$ que seria essa educação em um sentido amplo? E por que seria a base de toda e qualquer forma de sociedade? Quem pode nos auxiliar na busca dessas respostas é Jaeger (1995, p. 3). Segundo o autor,

Todo povo que atinge um certo grau de desenvolvimento sente-se naturalmente inclinado à prática da educação. Ela é o princípio por meio do qual a comunidade humana conserva e transmite a sua peculiaridade física e espiritual. Com a mudança das coisas, mudam os indivíduos; o tipo permanece o mesmo. (...) Antes de tudo, a educação não é uma propriedade individual, mas pertence por essência à comunidade. $\mathrm{O}$ caráter da comunidade imprime-se em cada um dos seus membros e é no homem, muito mais que nos animais, fonte de toda ação e de todo comportamento. (...) A educação participa na vida e no crescimento da sociedade, tanto no seu destino exterior como na sua estruturação interna e desenvolvimento espiritual; e, uma vez que o desenvolvimento social depende da consciência dos valores que regem a vida humana, a história da educação está essencialmente condicionada pela transformação dos valores válidos para cada sociedade.

Mediante a afirmação de Jaeger (1995), compreende-se que a educação corresponde aos valores, conhecimentos, hábitos, ideias, habilidades, comportamentos criados e desenvolvidos pelos homens, enfim, à forma adquirida pelas relações sociais e de produção no tempo e espaço, criando as condições para a manutenção e reprodução da vida social, para a sobrevivência dos indivíduos sociais, conduzindo e orientando seu modo de ser e estar no mundo, com o mundo e com os outros homens. Independente do tempo e espaço, porém, há um dado de continuidade (permanência) na descontinuidade (mudança) do desenvolvimento histórico da vida humana que interliga e medeia todas as gerações de homens: o fato de o ser social ser, antes de tudo, um ser natural, de modo que os seres humanos são, concomitantemente, diversos e semelhantes entre si em razão da sua unidade biológica (corpo biofísico, espécie humana). Importante frisar que a diversidade dos modos de vida e seus desdobramentos, que são os hábitos, comportamentos, tipos de atividades desenvolvidas, etc., têm como momento fundante as condições e circunstâncias do meio físico-natural-material, ainda que o mesmo possa ser mudado pelo intermédio da intervenção humana. Esse, todavia, é o âmago da questão; a mudança somente é possível se os homens 
dominarem o conhecimento dos meios para realizar a transformação de suas prévias ideações, o que depende do patamar do patrimônio histórico-cultural acumulado e elaborado pelo conjunto dos homens. Por isso mesmo não é a cultura que funda o ser social e sua historicidade e diversidade, mas, sim, o trabalho humano e as condições materiais com as quais se depara, enfrenta e responde.

Ainda segundo a assertiva de Jaeger (1995), quem educa é a sociedade, a comunidade. Como enfatiza Marx nas Teses sobre Feuerbach (Marx, 1963, p. 208, 209),

A teoria materialista de que os homens são produto das circunstâncias e da educação e de que, portanto, homens modificados são produto de circunstâncias diferentes e de educação modificada, esquece que as circunstâncias são modificadas precisamente pelos homens e que o próprio educador precisa ser educado. (...) A coincidência da modificação das circunstâncias e da atividade humana só pode ser apreendida e racionalmente compreendida como prática transformadora.

Logo, como explica Orso (2013, p. 57),

Marx reforça a tese de que, quem de fato educa o homem é a sociedade, tanto pelas pessoas que a fazem quanto pelas condições em que vivem. A educação corresponde ao nível de desenvolvimento das forças produtivas e das relações de produção de cada sociedade, em cada época. Assim a educação se transforma ou é transformada à medida em que também se transforma a sociedade, em que a luta se acirra. Novas relações de produção exigem novas relações sociais.

Voltando a Jaeger (1995), a educação integra e constitui o ser social, justificando e plenificando de sentido seu modo de vida, a forma como está sendo, como sente, pensa, age e se comporta. É por seu intermédio que os homens atribuem valor às situações, aos fatos e a si mesmos. Ela nos forma e define enquanto indivíduos sociais, auxiliando a fundamentar o que estamos sendo, mas questionando sobre o que verdadeiramente somos, devemos e podemos 
ser, dado que a humanidade dos homens é devir que se desenvolve enquanto possibilidade de realização que necessita criar as condições adequadas para se atualizar em ato.

Ainda sobre a educação em sentido amplo, deve-se considerar as respectivas afirmações de Tonet (2005, p. 222) e Saviani (2008, p. 13. Os parênteses são nossos), ao esclarecerem que:

\begin{abstract}
A natureza essencial da atividade educativa consiste em propiciar ao indivíduo a apropriação de conhecimentos, habilidades, valores, comportamentos, etc. que se constituem em patrimônio acumulado e decantado ao longo da história da humanidade. Nesse sentido, contribui para que o indivíduo se construa como membro do gênero humano e se torne apto a reagir diante do novo de um modo que seja favorável à reprodução do ser social na forma que ele se apresenta num determinado momento histórico.

(Sua especificidade) é produzir seres humanos, pois o que não é garantido pela natureza tem que ser produzido historicamente pelos homens, e aí se incluem os próprios homens. (Já o seu objeto) está relacionado, de um lado, à identificação dos elementos culturais que precisam ser assimilados pelos indivíduos da espécie humana para que eles se tornem humanos, e por outro, à descoberta das formas mais adequadas para atingir esse objetivo.
\end{abstract}

Trata-se de ponderações que complementam as observações feitas por Jaeger, demonstrando que a educação é parte do processo de tornar-se homem do homem, de sua autoconstrução, do desenvolvimento de produções genuinamente humanas que constroem a riqueza e a diversidade do ser social pela afirmação das individualidades e suas singularidades, objetivadas em diferentes obras, materiais e imateriais, que são apropriadas por outras subjetividades produzindo aquilo que denominamos de gênero humano. Conforme Tonet (2005, p. 213-215):

como membros da espécie, todos os indivíduos têm características comuns, que são transmitidas por herança genética. $\mathrm{O}$ seu pertencimento ao gênero humano, porém, não lhes é dado por herança genética, mas por um processo histórico-social, ou seja, pela incorporação das objetivações que constituem o patrimônio deste gênero. (...) Entre os homens (...) este processo é dirigido, e em grau cada vez maior, pela consciência. $\mathrm{O}$ homem, ao contrário dos animais, não nasce "sabendo" o que deve fazer para dar continuidade à sua 
existência e à da espécie. Deve receber este cabedal de instrumentos de outros indivíduos que já estão de posse deles. (...) (Porém,) não se trata apenas de tomar posse de algo que já está pronto e acabado. Trata-se, também, neste processo, de apropriar-se do que já existe e de, ao mesmo tempo, recriá-lo e renová-lo, configurando, desse modo, o próprio indivíduo em sua especificidade. (...) Assim, a problemática da educação reenvia ao problema no qual ela se fundamenta: sua essência consiste em influenciar os homens para que reajam de modo desejado diante das novas alternativas de vida.

A educação em si, e a atividade educativa, pautada na compreensão de seu sentido amplo, informal e histórico-ontológico, ou seja, enquanto autoconstrução consciente e consequente do ser social, do seu mundo e modo de vida, pauta-se na construção dos valores que devem orientar, justificando as ações humanas e suas criações, bem como as diretrizes traçadas para o desenvolvimento humano, podendo contribuir para que seja humanizador ou desumanizador, formador ou deformador, dado que a apropriação e a recriação do patrimônio histórico-cultural, acumulado pela humanidade por uma certa geração de homens em um período histórico-social determinado, pode servir tanto para libertá-la quanto para aprisioná-la, tornando-a serva de uma parcela dessa mesma humanidade. Daí a importância indiscutível de que os meios e ações estejam de acordo e qualifiquem os fins a alcançar, qual seja, a realização na plenitude possível das potencialidades e capacidades de todos os seres humanos.

É assim que se compreende a relevância vital dos fundamentos antropológicos para a educação - considerando sua natureza essencial e sua especificidade -, ou seja, questionar, problematizando, o homem e as condições para a estruturação, desenvolvimento, dinamismo da vida social, tendo por pressuposto as situações e circunstâncias favoráveis à realização dos seres humanos, promovendo a riqueza social pela diversidade das individualidades que encontram na realidade os meios e condições para se objetivar. Podemos, assim, compreender também a relação entre os fundamentos antropológicos e a pedagogia, considerando que esta última

se nutre do ser humano como problema de si mesmo, ou da problematização do sermos, do fazer-nos e formar-nos humanos. Seu objeto de teorização é a trágica descoberta de nós mesmos. A pedagogia acompanha ao longo da histó- 
ria as indagações do fazer-nos problema e nós mesmos, do como formar-nos. (...) $\mathrm{O}$ objeto da pedagogia é a humanização. (...) Pedagogia como acompanhamento das possibilidades de sermos humanos, de realização do humano possível que há na infância e em cada ser humano (Arroyo, 2003, p. 35-36).

Em termos gerais, antropológicos, é resgatar e refundar o homem, demonstrando sua centralidade objetiva (porque é ele quem constrói e organiza culturalmente o mundo humano) e ontológica, porque é ele mesmo quem se faz, questionando como está se fazendo, em quais valores está alicerçando e edificando seu modo de vida, para onde tais valores e os comportamentos/atitudes deles decorrentes o estão levando, e se é nessa direção e caminho que, de fato, quer-se e deve-se estar. Antropologia, educação e pedagogia não somente podem como devem travar um diálogo intempestivo e produtivo no intuito de redimensionalizar as formas do viver, saber, sentir, agir e pensar humanos.

Infelizmente, não é no sentido amplo, na natureza essencial da educação e dos seus fundamentos antropológicos que a antropologia se parametra em sua aproximação e aplicação no campo educativo. Há, na verdade, uma grande confusão e falta de compreensão dessa dimensão ontológica da educação e do próprio caráter antropológico do homem. A evidência pode ser constatada por meio da escola particularista-culturalista fundada por Franz Boas. As pesquisas de campo (trabalho etnográfico) e as reflexões desenvolvidas no campo educacional são interessantes, mas têm um alcance limitado justamente pela carência de uma visão e compreensão dialética, materialista, de totalidade social. Partamos à exposição dos fatos, em linhas gerais.

\section{Antropologia e Educação pela Perspectiva Particularista-Culturalista de Boas e seus Discípulos - contribuições e limites}

Como relata Gusmão (1997), foram realizadas aproximações entre a antropologia e a educação já no final do século 19. "A antropologia tentava compreender uma possível cultura da infância e da adolescência. Eram temas 
de suas pesquisas e de seus debates os processos interculturais infantis e os sistemas educativos informais, dentro de uma concepção alargada de educação" (p. 11).

Como se pode constatar pela afirmação, o ponto de partida é a cultura, ou seja, os comportamentos, os hábitos, os valores, as ideias, os ritos, etc., aprendidos na e por meio da convivência social, tanto com os mais experientes quanto com os da mesma faixa etária, com ênfase no ensino-aprendizagem das práticas cotidianas, isto é, na educação informal aprendida nas relações sociais e de produção (atividades produtivas, trabalho). Aqui, negligencia-se um dado essencial: o fato de que essas práticas, antes de serem culturais, são práticas socioeconômicas, ou pertencentes a determinados segmentos sociais de classe, pois a cultura é produzida por meio de um chão material, que corresponde ao lugar que os indivíduos sociais estão na estrutura produtiva e a função que ocupam na divisão técnica-social-hierárquica do trabalho, o que possibilita que vivam de uma determinada forma e não de outra, frequentem determinados lugares e não outros, ajam de uma maneira e não outra, pensem de um modo e não outro, tenham uma visão de mundo e não outra, e assim sucessivamente, acessem ou não, beneficiem-se ou não, das forças produtivas e do patrimônio histórico-cultural.

Mesmo considerando a educação em uma concepção ampla, não podemos esquecer que se trata de uma educação contextualizada historicamente, isto é, de uma educação configurada segundo as necessidades impostas pela sociabilidade capitalista, portanto, uma sociedade de classes que cria e reproduz uma educação de classes, algo que nunca é demais frisar. Logo, as práticas socioculturais da sociedade de classes reproduzem valores e uma visão de mundo que justifica e repõe, naturalizando as desigualdades sociais. A compreensão da natureza essencial da atividade educativa, de sua especificidade é propositalmente distorcida e desvirtuada, ocupando e responsabilizando a educação por ações e atividades que caberiam às políticas públicas estatais - educação compensatória -, como explica Saviani (2004). Assim, na sociedade capitalista a educação em 
sentido amplo também não encontra lugar, sobrevivendo somente no seu paralelo de educação popular e informal, que, na maioria das vezes, também não tem ciência da natureza essencial da educação.

É, porém, mediante a perspectiva particularista-culturalista, fundada por Franz Boas, em contraposição à teoria evolucionista de seu mestre Lewis Henry Morgan, e desenvolvida por seus seguidores, que as relações entre antropologia e educação vão se estreitando, principalmente com os estudos de Margareth Mead e Ruth Benedict. Vale ressaltar que, ao longo de sua vida, Mead se debruçou ao estudo da educação e fez importantes contribuições, como destaca Dauster (2007, 1997):

Nos anos 30 do século passado, a antropóloga americana Margareth Mead fez da educação objeto privilegiado da Antropologia no interior da escola Cultura e Personalidade. Sua obra clássica intitulada Growing up in New Guinea buscava entender como valores, gestos, atitudes e crenças eram inculcadas nas crianças pelos adultos com o objetivo de formá-los para viver dentro de sua sociedade. A autora investigou, tanto os modos de transmissão das gerações mais velhas para as mais novas, como a própria formação da personalidade e as formas de aprendizagem existentes. Essa referência é particularmente importante, uma vez que a antropóloga demonstrou, ao lado da dimensão científica, a preocupação pedagógica, buscando, a partir de sua experiência etnográfica, influenciar as atitudes face às crianças e aos adolescentes no seu país, no sentido de uma menor repressão. A pesquisadora mostrou que a adolescência, com as características conhecidas por nós, é um fenômeno sociocultural e não uma questão fisiológica. Ou seja, os comportamentos, as atitudes, as crises de crescimento não podem ser reduzidas a fatores biológicos, orgânicos ou hormonais (2007, p. 19).

Esta abordagem revelava as especificidades culturais, travando um intenso diálogo com a psicologia e a psicanálise, tendo em vista sustentar a existência de "personalidades culturais" (1997, p. 39).

Como dissemos, é inegável que o culturalismo e o trabalho desenvolvidos por seus pesquisadores e seguidores trazem importantes contribuições, como o de Mead, supracitado, responsável por uma nova compreensão e perspectiva de análise em relação aos fatores que influenciam e determinam a conformação da personalidade, comportamento, hábitos das crianças e adolescentes que não 
os físico-naturais, biológicos, orgânicos ou hormonais, redimensionalizando a perspectiva educacional e a teoria pedagógica. Novamente, porém, está ausente uma análise sólida das situações concretas que embasam a construção desses comportamentos e personalidades culturais, que têm como base as questões e as condições materiais de existência a que essas crianças e adolescentes têm, ou não, acesso para se formar e se desenvolver. A fim de evitar distorções e malentendidos, passamos a palavra para aqueles que tão bem a compreenderam e definiram a partir de sua práxis social: Marx (1978) e Engels (2009):

O resultado geral a que cheguei e que, uma vez obtido, serviu-me de fio condutor aos meus estudos, pode ser formulado em poucas palavras: na produção social da própria vida, os homens contraem relações determinadas, necessárias e independentes de sua vontade, relações de produção estas que correspondem a uma etapa determinada de desenvolvimento das suas forças produtivas materiais. A totalidade dessas relações de produção forma a estrutura econômica da sociedade, a base real sobre a qual se levanta uma superestrutura jurídica e política, e a qual correspondem formas sociais determinadas de consciência. $O$ modo de produção da vida material condiciona o processo em geral de vida social, político e espiritual. Não é a consciência dos homens que determina o seu ser, mas, ao contrário, é o seu ser social que determina sua consciência. (...) Com a transformação da base econômica, toda a enorme superestrutura se transforma com maior ou menor rapidez. Na consideração de tais transformações é necessário distinguir sempre entre a transformação material das condições econômicas de produção, que pode ser objeto de rigorosa verificação da ciência natural, e as formas jurídicas, políticas, religiosas, artísticas ou filosóficas, em resumo, as formas ideológicas pelas quais os homens tomam consciência deste conflito e o conduzem até o fim. Assim como não se julga o que um indivíduo é a partir do julgamento que ele se faz de si mesmo, da mesma maneira não se pode julgar uma época de transformação a partir de sua própria consciência; ao contrário, é preciso explicar esta consciência a partir das contradições da vida material, a partir do conflito existente entre as forças produtivas sociais e as relações de produção (1978, p. 129-130. Grifos nossos).

Segundo a concepção materialista da história, o fator que em última instância determina a história é a produção e a reprodução da vida real. Nem Marx nem eu nunca afirmamos mais do que isso. Se alguém o tergiversa dizendo que o fator econômico é o único determinante, converte aquela tese numa frase vazia, abstrata, absurda. A situação econômica é a base, mas os diver- 
sos fatores da superestrutura - as formas políticas da luta de classes e seus resultados, as Constituições que, uma vez ganha uma batalha, são redigidas pela classe vitoriosa etc., as formas jurídicas, e mesmo os reflexos de todas estas lutas reais no cérebro dos participantes, as teorias políticas, jurídicas, filosóficas, as ideias religiosas e o seu desenvolvimento ulterior até serem convertidas em sistemas dogmáticos-exercem igualmente a sua ação sobre o curso das lutas históricas e, em muitos casos, determinam predominantemente sua forma (...) Somos nós mesmos que fazemos a história, mas, nós a fazemos, em primeiro lugar, segundo premissas e condições muito concretas. Entre elas, são as econômicas as que, em última instância, decidem. Mas também desempenham um papel, ainda que não seja decisivo, as condições políticas e até as tradições que rondam como um duende nas cabeças dos homens... O fato de que os discípulos destaquem mais que o devido o aspecto econômico é coisa que, em parte, temos culpa Marx e eu mesmo. Frente aos adversários, tínhamos que sublinhar este princípio cardinal que era negado, e nem sempre dispúnhamos de tempo, espaço e ocasião para dar a devida importância aos demais fatores que intervém no jogo das ações e reações. Infelizmente, ocorre com frequência que se crê haver entendido totalmente e que se pode manusear sem dificuldades uma nova teoria pelo simples fato de se haver assimilado, e nem sempre exatamente, suas teses fundamentais. Desta crítica não estão isentos muitos dos novos "marxistas" e assim se explicam muitas das coisas inexpressivas com que contribuíram (apud Quintaneiro et. al., 2009, p. 38-39. Grifos nossos).

São as condições materiais de existência, em última instância, como enfatizam Marx e Engels, que determinam as práticas socioculturais e a possibilidade ou não de realização da diversidade humana, e somente a tomada de consciência dessa realidade objetiva, e não representativa, pode fazer com que a classe que está obstruída e mutilada em seu desenvolvimento radicalize a luta pela realização das condições que lhe permitam desenvolver-se e realizar-se na plenitude do patamar do patrimônio histórico-cultural alcançado pelos homens e posto pelo nível do desenvolvimento histórico-social das forças produtivas.

Voltando as relações entre antropologia e educação, Neusa Maria Gusmão considera que, "como ciência e, em particular, como ciência aplicada, antropologia e antropólogos estiveram, no passado e no presente, preocupados com o universo das diferenças e das práticas educativas" (1997, p. 12). Novamente perguntamos: De que diferenças falamos? De habilidades, de interesses? Esta 
é a base para a criação da riqueza humana, criada pela realização das atividades singulares específicas a cada indivíduo, cujas produções e objetivações contribuem para que outros, a partir da apropriação delas, desenvolvam suas próprias produções e objetivações. Na verdade, o que chamam de diferença é fruto da desigualdade de condições isonômicas para o desenvolvimento integral das individualidades, originalmente abortado por um modo de produção que se estrutura na propriedade privada da riqueza socialmente produzida, na divisão técnica-hierárquica-burocrática do trabalho, cindindo trabalho manual e intelectual, dimensões essenciais de qualquer ato produtivo-teleológico humano.

Deveríamos, portanto, falar dos fundamentos da desigualdade social entre os homens que impede, obstaculiza e inviabiliza a realização do trabalho humano como ato de vontade e liberdade, como dito em outro momento, e também a negação das condições que deveriam ser pressupostas para a efetivação da diversidade humana. Sendo assim, as práticas educativas estão de acordo com as práticas socioeconômicas que as fundamentam, que é a reprodução das desigualdades sociais, de uma escola, um ensino e uma aprendizagem dual e diferenciada em termos de conteúdos e métodos para os filhos da elite e para os filhos da classe trabalhadora. A verdadeira diversidade humana somente poderá aflorar quando a sociedade de classes e a educação de classes que ela sistematiza e estrutura institucionalmente, for superada e transcendida positivamente por uma nova organização societal.

A educação escolar, por conta de sua própria natureza - ou seja, por ser um aparelho de Estado e de um Estado capitalista, que inculca e reproduz a ideologia dominante, que é a da classe dominante, possibilita a construção da aceitação de sua dominação, legitimando-a socialmente, tornando-se, assim, classe hegemônica -, tem um campo de atuação limitado, restringindo as possibilidades de atividades educativas de caráter transformador, por isso mesmo ficando apenas em caráter, como experiência para se ter o gosto, vivenciar a possibilidade de fazer diferente, de contra-hegemonia, que pode despertar para o engajamento nas lutas que se travam no âmbito da sociedade para além dos muros das instituições de ensino. Como demonstra Harper (apud Orso, 2013, p. 55), as atividades e experiências de caráter transformador, 
(...) ao aproveitarem as brechas existentes e ao utilizarem os espaços disponíveis, esgotam o campo do possível no interior do sistema escolar. Os educadores, os pais de alunos e os estudantes que conseguirem criar esses espaços de liberdade e de experimentação fazem de sua prática educativa uma negação viva do modo de organização social dominante e do tipo de escola seletiva e elitista que lhe é funcional.

Essa é mais uma constatação de que "as relações culturais estão submersas em relações de poder e, como tais, dizem respeito a realidades mais amplas, estruturadas em torno de relações de classe e baseadas em mecanismos de desigualdade e dominação" (Gusmão, 1997, p. 21-22). Não queremos, com isso, negar a importância das atividades educativas de caráter transformador dentro das instituições escolares, de ensino, mas não podemos superestimar seu alcance e resultados, como também não podemos perder de vista o fato de que são ações estruturalmente limitadas, e que "a educação, quer formal, quer informal, sempre terá um caráter predominantemente conservador" (Tonet, 2005, p. 223). Nesse ínterim,

A existência do antagonismo de classe também implica no surgimento - sob formas explícitas ou implícitas - de outras propostas, com outros fundamentos, outros valores e outros objetivos. De modo que o campo da educação, como aliás toda a realidade social, é um espaço no qual se trava uma incessante luta, ainda que a hegemonia esteja sempre nas mãos das classes dominantes. Essas outras propostas, no entanto, sempre terão um caráter restrito, pontual, isolado. No caso da sociedade atual, uma proposta de educação emancipadora só poderá ser explicitada em seus elementos gerais, mas nunca poderá ser levada à prática como um conjunto sistematizado. A disputa certamente pode e deve ser efetuada, posto que o processo histórico, sendo constituído de atos humanos individuais marcados por algum grau de liberdade, não tem os seus resultados previamente determinados. E deve ser efetuada nos mais diversos campos: das ideias, dos conteúdos, dos programas, dos métodos, dos recursos, dos espaços, das tecnologias, das políticas educacionais, etc. Não se pode nutrir, todavia, a ilusão de estruturar uma educação emancipadora como um conjunto sistematizado e amplamente praticável em oposição a uma educação conservadora (Tonet, 2005, p. 223). 
O raciocínio de Tonet (2005) pode ser complementado pelas reflexões desenvolvidas por Orso (2013). Apesar da citação ser longa, as ponderações tecidas pelo autor são muito esclarecedoras e pertinentes, sendo imprescindível sua transcrição literal, algo que não podemos dispensar. Assim, segundo Orso (2013, p. 56-58),

(...) a educação não é propriamente reprodutora nem redentora, também não é revolucionária. Ela expressa as contradições e a própria sociedade em que está inserida. A sociedade estabelece os limites e as possibilidades da educação; estabelece sua qualidade e sua quantidade, sua forma e seu conteúdo. Isto significa que lutar somente pela educação, é lutar em vão; que é necessário lutar pela educação lutando simultaneamente pela transformação da sociedade. Pois, "a exigência de abandonar as ilusões sobre sua condição é a exigência de abandonar uma condição que necessita de ilusões".

Mas, a superação das ilusões, bem como daquilo que as produz, não ocorre por um ímpeto voluntarista. Entretanto, nessas condições o acesso ao conhecimento científico, que se identifica com o domínio da organização e do funcionamento da realidade, aparece como uma condição sine qua non à transformação, mas não suficiente por si só. $\mathrm{O}$ acirramento das contradições e dos antagonismos sociais desencadeiam as condições para a mobilização social. Até não se apresentar uma situação limite em que esteja em jogo a sobrevivência do homem, imperará o individualismo, a competição, a concorrência, a busca de saída de tipo personalista e, no geral, de cada um a suas custas. Se a base material exige o estabelecimento de relações necessárias e independentes da vontade, somente no momento em que uma situação nova revelar a insuficiência das relações anteriores e exigir outras novas, elas serão desencadeadas.

De que adianta "dizer" que é preciso mudar de mentalidade, que é preciso deixar de ser individualista, que é preciso ser solidário, que é preciso pensar no outro, que é preciso ser fraterno, que é preciso deixar o egoísmo de lado, se isso não passar de palavras de efeito e de tipo moralistas? Por isso, é necessário considerar o modo como a sociedade está organizada para garantir a sobrevivência. As pessoas até podem não querer explorar e dominar os outros; podem querer ser fraternas e solidárias, mas são forçadas a fazer o contrário devido ao modo de produção dominante. (...) Dessa forma, impõe-se, mais do que nunca, conhecer cada vez melhor a sociedade, conhecer como ela se movimenta, como se transforma, para poder intervir nela nos momentos adequados. A verdadeira aprendizagem se dá na luta concreta, na percepção 
de que a sociedade de classes e a sociedade capitalista é inviável ao ser humano; na destruição das promessas e ilusões burguesas. Isso ocorre com as transformações sociais, que vão provocando novas relações e que, por sua vez, vão minando o sistema e desencadeando novas formas de se organizar e se viver socialmente. As formas de organização baseada no individualismo e na competitividade, vão sendo superadas por formas de organização baseadas no coletivo e na cooperação, na negação do individualismo; vão rompendo com o personalismo e com a competitividade e levam à descoberta da necessidade de luta, de cooperação e do outro.

Vemos, nas citações de Tonet (2005) e Orso (2013), a contradição que permeia a educação escolar, pois estruturalmente é conservadora - admitindo progressos, mudanças como forma de manter a ordem e a aceitação social para sua legitimidade - e limita ações mais radicais que contestem e se contraponham ao sistema capitalista vigente. Por outro lado, pode, dependendo da forma como for transmitido, (re)construído, assimilado e (re)elaborado o patrimônio histórico-cultural acumulado pela humanidade, contribuir para o processo de tomada de consciência dos sujeitos objetos da educação, dado que tem o poder de persuadi-los a acatar e abraçar, incorporando e reproduzindo, uma determinada perspectiva de classe e de mundo e não outra, passando a perceber e compreender o mundo e sua relação com ele a partir desse posicionamento de classe, influenciando na escolha entre as alternativas postas para estes sujeitos, ainda que elas sejam delimitadas e limitadas por sua condição socioeconômica e inserção produtiva. Ainda assim, todavia, sempre há, como ressaltou Tonet (2005), brechas e margens para as ações individuais que podem ser um diferencial, provocando e desacomodando outros indivíduos que se veem obrigados a também tomar uma posição, auxiliando na identificação de que lado estão: da humanização e realização humanas, que têm como fundamento os valores e necessidades humanos; ou da humanização desumanizadora, que tem como fundamento os valores e necessidades do capital, que forma(ta) deformando. Afinal, como assevera Orso (2013, p. 62. Os parênteses são nossos), “cabe ao professor, por meio do trabalho que realiza, ajudar a preparar os alunos para uma nova sociedade; a ajudar ao aluno transitar do estado de consciência alienada (senso comum) para a superação de seu estado de classe (consciência históricofilosófica); servir de ponte entre a realidade atual e a que se quer construir". 
Por fim, apesar das suas contribuições destacando aspectos relevantes acerca das relações socioculturais, a perspectiva particularista-culturalista encontra seu limite no fato de não compreender que esses comportamentos, rituais, ideias, modos de viver, ser, sentir e pensar são, em última instância, condicionados pelas relações materiais de produção.

\section{Considerações Finais}

Ao longo das análises e reflexões iniciais tecidas neste artigo, procurou-se expor e defender que os fundamentos antropológicos para a educação devem se pautar no questionamento e (re)descoberta dos valores essenciais que real e concretamente favoreçam, na plenitude possível do patamar alcançado pelas forças produtivas e pelo patrimônio histórico-cultural acumulado pela humanidade, o desenvolvimento e realização humana. A consciência do seu ser "em si” (o homem e sua humanização e hominização como problemas) poderá criar as condições objetivas para que os seres humanos se coloquem "para si”, ou seja, para o outro enquanto condição para realização e desenvolvimento de si mesmo, indo além do dito "respeito à alteridade". É a compreensão de que eu não sou eu, nem sou o outro, de que todos somos, na verdade, qualquer coisa de intermédio. Sou, somos e estamos sendo o que nos permite a relação que estabelecemos e construímos. Por isso mesmo, a condição para que eu seja livre é que o outro também seja. Somente poderei ser efetivamente livre se e quando o outro também for, de modo que a liberdade do outro é condição para a minha liberdade. Saviani (2004, p. 37-38) elucida:

$\mathrm{O}$ fato de não ser indiferente à pessoa dos outros, o fato de reconhecer o valor do outro, a sua liberdade, indica que o homem é capaz de transcender a sua situação e as opções pessoais para se colocar no ponto de vista do outro, para se comunicar com o outro, para agir em comum com ele, para ver as coisas objetivamente. E aqui se abre ao homem outro campo amplo para a valoração e os valores. Ver as coisas objetivamente significa aceitar o valor da verdade. E esta transcende as pessoas como tais tornando-se fonte de comunicação e entendimento entre os homens. (...) a relação horizontal do homem para com os outros será uma relação de colaboração. (...) E outro campo se abre ao 
homem para a valoração e os valores: são as formas estéticas, a apreciação das coisas e das pessoas pelo que elas são em si mesmas, sem outro objetivo senão o de relacionar-se com elas.

Enfim, transcender, se libertar e superar o ethos capitalista, as ilusões produzidas pela sociedade capitalista de classes, as prisões deformadoras do trabalho assalariado e cindido entre trabalho manual e intelectual, que desvirtua o significado humanizador do trabalho como protoforma do ser social e como ato de vontade e liberdade para a realização na plenitude possível dos seres humanos, são conquistas que devem ser galgadas pelo acirramento das lutas de classe travadas no âmbito da sociedade e da estrutura produtiva, produzindo formas de enfrentamento e experiências alternativas, que criem outros e novos valores para a mudança do processo de valoração pelos homens, onde resgatem e retomem os valores essenciais (antropológicos) para o bem comum e a vida boa para toda a humanidade, tendo como parâmetros norteadores o coletivo, a vida social - que cria as condições para a realização e desenvolvimento individual -, a cooperação e o eu e o outro em relação.

Importa, portanto, tomar consciência do que funda e fundamenta o homem como homem: o trabalho, e não a cultura; que as necessidades criadas pelos homens precisam estar em consonância com o que ele realmente é e pode vir a ser enquanto vitalidade criadora, orientando e guiando suas ações por meio de valores e valorações que cultivem e propaguem a apreciação das coisas e das pessoas pelo que elas são em si mesmas, partindo do pressuposto e princípio que aquilo que justifica a relação entre os homens é a necessidade do outro como condição de descoberta de si mesmo. Essas são questões elementares para uma formação e autoconstrução humanas objetiva e concretamente humanizadoras, fundamentando as bases antropológicas para a educação em um sentido amplo, escolhendo os meios mais adequados que qualifiquem, e estejam de acordo, a sua natureza essencial.

\section{Referências}

ARROYO, Miguel G. Pedagogias em movimento - o que temos a aprender dos movimentos sociais? Currículo sem Fronteiras, v. 3, n 1, p. 28-49, jan./jun. 2003. 
DAUSTER, Tania. Um outro olhar: entre a antropologia e a educação. In: ZAMBONI, Ernesta (Coord.). Antropologia e educação - interfaces do ensino e da pesquisa. Caderno Cedes, ano XVIII, n. 43, dez. 1997.

. Um saber de fronteira - entre a antropologia e a educação. In: DAUSTER, Tania. (Org.). Antropologia e educação - um saber de fronteira. 1. ed. Rio de Janeiro: Forma \& Ação, 2007. (Fundamentos da educação; 4).

ENGELS, Friedrich. Apêndice - humanização do macaco pelo trabalho. In: ENGELS, Friedrich. A dialética da natureza. 3. ed. Rio de Janeiro: Paz e Terra, 1979. (Pensamento Crítico).

FISCHER, Ernest. As origens da arte. In: FISCHER, Ernest. A necessidade da arte. Trad. Leandro Konder. 4. ed. Rio de Janeiro: Zahar Editores, 1959.

FREIRE, Paulo. Pedagogia do oprimido. 45. ed. Rio de Janeiro: Paz e Terra, 2005.

GUSMÃO, Neusa Maria. Antropologia e educação: Origens de um diálogo. In: ZAMBONI, Ernesta (Coord.). Antropologia e educação - interfaces do ensino e da pesquisa. Caderno Cedes, ano XVIII, n. 43, dez. 1997.

JAEGER, Werner Wilhelm. Paideia - a formação do homem grego. Trad. Artur M. Parreira. Adaptação para a edição brasileira Monica Stahel. Revisão do texto grego Gilson Cesar Cardoso de Souza. 3. ed. São Paulo: Martins Fontes, 1995.

LESSA, Sérgio. A ontologia de Lukács. Maceió: Edufal, 1996. (Didática - Edufal; 2).

MARTINS, Fernando José. Formação de professores e lutas de classes. In: ORSO, Paulino José; GONÇALVES, Sebastião Rodrigues; MATTOS, Valci Maria (Orgs.). Educação e luta de classes. 2. ed. São Paulo: Expressão Popular, 2013.

MARX, Karl. Manuscritos econômicos-filosóficos e outros textos escolhidos. Trad. José Carlos Bruni (et al.). 2. ed. São Paulo: Abril Cultural, 1978. (Os Pensadores).

MARX, Karl; ENGELS, Friedrich. Obras escolhidas. v. 3. Rio de Janeiro: Editorial Vitória, 1963.

ORSO, Paulino José. A educação na sociedade de classes: possibilidades e limites. In: ORSO, Paulino José; GONÇALVES, Sebastião Rodrigues; MATTOS, Valci Maria (Orgs.). Educação e luta de classes. 2. ed. São Paulo: Expressão Popular, 2013.

QUINTANEIRO, Tania et al. Um toque de clássicos: Marx, Durkheim e Weber. 2. ed. rev. e atualizada. Belo Horizonte: Editora UFMG, 2009.

SAVIANI, Demerval. Escola e democracia - teorias da educação, curvatura da vara, onze teses sobre a educação política. 39. ed. Campinas, SP: Autores Associados, 2007. (Coleção Polêmicas do Nosso Tempo). 
Pedagogia histórico-crítica: primeiras aproximações. 10. ed. rev. Campinas, SP: Autores Associados, 2008. (Coleção educação contemporânea).

. Valores e objetivos na educação. In: SAVIANI, Dermeval. Educação: do senso comum à consciência filosófica. 15. ed. Campinas, SP: Autores Associados, 2004. (Coleção Educação Contemporânea).

TONET, Ivo. Educação e emancipação humana. In: TONET, Ivo. Educação, cidadania e emancipação humana. Ijuí: Ed. Unijuí, 2005. (Coleção fronteiras da educação).

Recebido em: 7/9/2015

Aceito em: 29/7/2016 